Article

\title{
Decoupling Greenhouse Gas Emissions from Crop Production: A Case Study in the Heilongjiang Land Reclamation Area, China
}

\author{
Yu Zhang ${ }^{(1)}$, Xiaojiao Zou, Caifen Xu and Qingshan Yang * \\ School of Geographical Science, Northeast Normal University, Changchun 130024, China; \\ zhangy221@nenu.edu.cn (Y.Z.); zouxj437@nenu.edu.cn (X.Z.); xucf 2016@163.com (C.X.) \\ * Correspondence: yangqs027@163.com; Tel.: +86-431-8509-9550
}

Received: 28 April 2018; Accepted: 4 June 2018; Published: 6 June 2018

check for updates

\begin{abstract}
Modern agriculture contributes significantly to greenhouse gas emissions in several ways. From the perspective of sustainability assessment, it is not enough to evaluate mitigation measures that rely only on emissions reductions. In this article, we use the method of decoupling analysis to construct a decoupling index based on carbon footprint and crop yield and evaluate the relationship between crop production and greenhouse gas emissions using the most modern grain production base in China as a case study. The results indicate that a weak but variable decoupling trend occurred from 2001 to 2015 and that each branch achieved on average a weak decoupling across the study period. In addition, rice production constituted $80 \%$ of the regional carbon footprint in a crop's life cycle. The results of our analysis of rice production show that weak decoupling was the most common outcome but was not consistent because a weak coupling occurred in 2015. Each branch on average achieved a weak decoupling except for the SH branch. Our research indicates that high agricultural material inputs with low utilization efficiency contributed to the poor relationship between crop production and greenhouse gas emissions in the study area. Fertilizer, especially $\mathrm{N}$ fertilizer, was an important contributor to the total greenhouse gas emissions of crop production. As a supplement to carbon footprint assessment, this decoupling analysis helps local decision-makers diagnose the level of green growth, identify key options to mitigate greenhouse gas emissions from agriculture, and adopt more targeted interventions towards sustainable agriculture.
\end{abstract}

Keywords: decoupling analysis; greenhouse gas emissions; carbon footprint; low-carbon agriculture

\section{Introduction}

The relationship between economic growth and environmental pressure has been intensively discussed [1-3]. In recent years, green economic growth has attracted worldwide attention as a way to maintain rapid economic development while limiting environmental degradation. Like the term "green economy," "decoupling" refers to the ability of an economy to grow without a corresponding increase in environmental pressure [4]. Today, decoupling environmental impacts from human well-being has been widely acknowledged by policy-makers, industry leaders, and civil society as a key issue to address in meeting sustainable development goals [5]. In the field of sustainability studies, following the environmental Kuznets curve (EKC) hypothesis [6], decoupling analysis has become increasingly popular, and there is a growing body of literature on the decoupling method and indicators of decoupling [7-12]. Indeed, as a policy goal, decoupling environmental impact from economic growth has been adopted by the European Union (EU) and the Green Economy Initiative of the United Nations Environment Program (UNEP) [13].

Climate change is one of the greatest challenges to mankind today. The increases in anthropogenic greenhouse gases (GHGs), including carbon dioxide $\left(\mathrm{CO}_{2}\right)$, methane $\left(\mathrm{CH}_{4}\right)$, and nitrous oxide $\left(\mathrm{N}_{2} \mathrm{O}\right)$, 
have important effects on global warming [14,15]. Many studies have empirically assessed the potential impact of human activities or production sectors on global warming by quantifying the carbon footprint (CF) [16-18]. Modern agriculture is usually accompanied by high material inputs, high energy consumption, and high release of pollutants, which all play an important role in GHG emissions [19]. Extensive studies have evaluated agricultural CFs associated with material inputs or based on life cycle assessment (LCA). LCA is a commonly used environmental management tool to assess a product or service from "cradle to grave" [20]. The literature on evaluating the CFs of crop production generally quantified the GHG emissions from sowing to harvest, including the indirect emissions from agricultural material inputs and the direct emissions from energy consumption for farm mechanical operations, $\mathrm{N}_{2} \mathrm{O}$ from $\mathrm{N}$ fertilizer use or the $\mathrm{CH}_{4}$ emissions from rice paddies [21-24]. Studies of CFs for a diverse range of crops have been performed at different geographical scales using national statistical data or farm survey data [17,25-28], and other studies have described a certain crop's CF in more detail, such as for rice [29-31], spring barley [32], and wheat [33]. In addition, GHG emissions under different cropping systems and farm management practices have been addressed in detail [21-23,34,35], and the CFs of crop production have also been compared across countries [27]. All these studies have helped to further explore measures to mitigate agricultural GHG emissions and have put forward potential solutions to develop low-carbon agriculture.

China is a major agricultural producer, and GHG emissions in the agricultural sector account for $17 \%$ of the national total [36]. According to previous studies, the CFs of crop production in China [37] were higher than those in the USA [27] and the UK [17] based on national statistical data. From the perspective of sustainability assessment, it is not enough to evaluate mitigation measures depending only on emissions reduction; similarly, it remains difficult to examine if one farming region has taken effective measures to reduce the carbon intensity of agriculture. The Heilongjiang land reclamation area (HLRA) is both the most modern grain production base and the largest green grain production base in China, the application of chemical fertilizers and pesticides in the HLRA is far below the national standard, and its crop yield per unit area exceeds that of the US [38]. However, it is not clear if its high crop yield occurs at the expense of high GHG emissions. In this study, we use this area as an example to estimate the extent to which GHG emissions are decoupled from crop production.

The objectives of this study are, first, to quantify the CFs of crop production (including rice, maize, soybeans, and wheat) using the LCA approach in the HLRA during 2001-2015; second, to determine the relationship between crop production and GHG emissions based on a decoupling index; and, last, to analyze the composition of the CFs of crop production and further provide targeted suggestions for decision-making for low-carbon agriculture.

The flowchart for the decoupling analysis is shown in Figure 1.

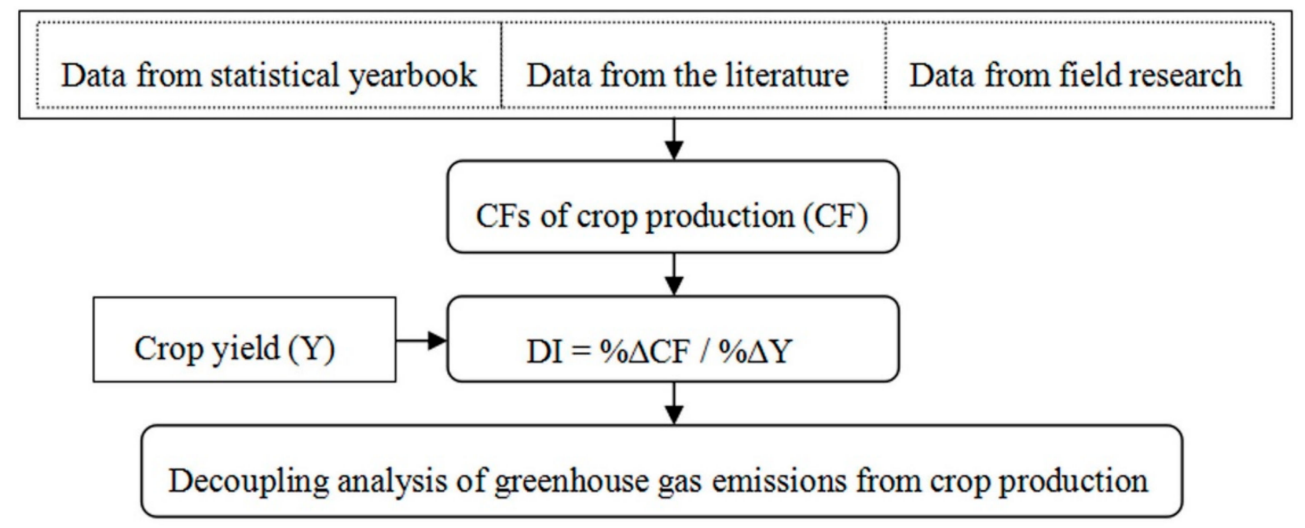

Figure 1. Steps in the decoupling analysis. 


\section{Materials and Methods}

\subsection{Carbon Footprint Calculation}

The carbon footprint of crop production was expressed in this study in $\mathrm{CO}_{2}$ equivalents (CE) following the LCA approach. GHG emissions included the direct and indirect emissions from crop production. The indirect emissions were attributed to the manufacture of agricultural material inputs (e.g., fertilizers, pesticides and plastic films) and electricity used for rice irrigation; the direct emissions were attributed to energy consumption from farm mechanical operations including seeding, tillage, transportation and harvesting as well as $\mathrm{N}_{2} \mathrm{O}$ from $\mathrm{N}$ fertilizer use and $\mathrm{CH}_{4}$ emissions from rice paddies [25].

GHG emissions from agricultural material inputs or sources were expressed as $C F_{i}$ (in $\mathrm{tCE}$ ) using Equation (1):

$$
C F_{i}=\sum\left(I_{i} \times E F_{i}\right),
$$

where $I_{i}$ is the amount of each agricultural input or source $i$, including fertilizers (in $\mathrm{t}$ ), pesticides (in $\mathrm{t}$ ), seed (in $\mathrm{t}$ ), plastic films (in $\mathrm{t}$ ), electricity for rice irrigation (in $\mathrm{kWh}$ ) and diesel for machinery (in $\mathrm{t}$ ), and $E F_{i}$ is the GHG emission factor in this study (Table 1).

The direct $\mathrm{N}_{2} \mathrm{O}$ emissions from fertilizer $\mathrm{N}$ use were expressed as $C F_{N 2 O}$ (in $\mathrm{tCE}$ ) using Equation (2):

$$
C F_{\mathrm{N}_{2} \mathrm{O}}=I_{\mathrm{N}} \times E F_{\mathrm{N}_{2} \mathrm{O}} \times \frac{44}{28} \times 298
$$

where $I_{N}$ represents the amount of $N$ fertilizer used (in $\mathrm{t}$ ), $E F_{N 2 O}$ is the emission factor for $\mathrm{N}_{2} \mathrm{O}$ emissions caused by $N$ fertilizer used (in $\mathrm{tN}_{2} \mathrm{O}-\mathrm{Nt}^{-1}$ ) [39,40], 44/28 is the ratio of molecular weights of $\mathrm{N}_{2} \mathrm{O}$ to $\mathrm{N}_{2}$, and 298 is the net global warming potential of $\mathrm{N}_{2} \mathrm{O}$ over a 100-year period [40].

The $\mathrm{CH}_{4}$ emissions from a submerged rice paddy in a single season were expressed as $\mathrm{CF}_{\mathrm{CH}}$ (in tCE) using Equation (3):

$$
C F_{\mathrm{CH}_{4}}=E F_{d} \times T \times A \times 25,
$$

where $E F_{d}$ is a daily emission factor (in $\mathrm{tCEha}^{-1} \mathrm{day}^{-1}$ ), $T$ is the rice growing period (in days), $A$ is the planting area (in ha), and 25 is the relative molecular warming forcing of $\mathrm{CH}_{4}$ in a 100-year period [40].

Here, $E F_{d}$ was estimated by Equation (4) due to the restricted condition of data:

$$
E F_{d}=E F_{c} \times S F_{w} \times S F_{p} \times S F_{m}
$$

where $E F_{c}$ is the basic emission factor for fields flooded without organic amendment; $S F_{w}$ and $S F_{p}$ are scaling factors for different hydrological conditions over the rice growing period and before rice transplanting, respectively; and $S F_{m}$ is a scaling factor for quantifying organic amendment used for rice production [41]. All of the above emission factors for agricultural inputs or sources are shown in Table 1.

The total carbon footprint $C F_{t}$ (in tCE) was calculated for rice production and for dry crop production (maize, soybeans, and wheat) by Equations (5) and (6), respectively:

$$
\begin{gathered}
C F_{t}=C F_{i}+C F_{N_{2} \mathrm{O}}+C F_{\mathrm{CH}_{4}} \\
C F_{t}=C F_{i}+C F_{\mathrm{N}_{2} \mathrm{O}} .
\end{gathered}
$$

Based on the estimated $C F_{t}$, carbon intensity in crop yield, $C F_{Y}$ (in $\mathrm{tCEt}^{-1}$ ), and the carbon intensity in crop area, $C F_{A}$ (in tCEha ${ }^{-1}$ ), were calculated using Equations (7) and (8), respectively, in terms of crop yield $(Y$, in $t)$ and crop planting area $(A$, in ha).

$$
C F_{Y}=\frac{C F_{t}}{Y}
$$




$$
C F_{A}=\frac{C F_{t}}{A}
$$

Table 1. Emission factors for agricultural inputs and sources.

\begin{tabular}{|c|c|c|c|}
\hline Emission Source & Abbreviation & Emission Factor & Reference \\
\hline Fertilizer & EFf & $\begin{array}{l}1.53 \mathrm{tCEt}-1 \text { ( } \mathrm{N} \text { fertilizer); } 1.63 \mathrm{tCEt}-{ }^{1} \\
\left(\mathrm{P} \text { fertilizer); } 0.66 \mathrm{tCEt}-{ }^{1} \text { (K fertilizer) }\right.\end{array}$ & {$[30]$} \\
\hline Pesticide & $\mathrm{EF}_{\mathrm{p}}$ & $\begin{array}{l}0.20 \mathrm{tCEt}-{ }^{1} \text { (Herbicide); } 16.60 \mathrm{tCEt}^{-1} \\
\text { (Insecticide) }\end{array}$ & [30] \\
\hline Plastic film & EFpf & $22.70 \mathrm{tCEt}-1$ & {$[30]$} \\
\hline Seed & $\mathrm{EF}_{\mathrm{s}}$ & $0.58 \mathrm{tCEt}-1$ & [26] \\
\hline Electricity for irrigation & $\mathrm{EF}_{\mathrm{e}}$ & $1.23 \times 10-3 \mathrm{tCEkWh}-1$ & [26] \\
\hline Diesel for machinery & $\mathrm{EF}_{\mathrm{d}}$ & $0.89 \mathrm{tCEt}-1$ & {$[30]$} \\
\hline $\mathrm{N}$ fertilizer-induced $\mathrm{N}_{2} \mathrm{O}$ & $\mathrm{EF}_{\mathrm{N} 2 \mathrm{O}}$ & $\begin{array}{l}0.01 \mathrm{tN}_{2} \mathrm{O}-\mathrm{Nt}-1 \\
0.0073 \mathrm{tN}_{2} \mathrm{O}-\mathrm{Nt}^{-1} \text { (Rice paddy) }\end{array}$ & {$[39,40]$} \\
\hline \multirow[t]{4}{*}{$\begin{array}{l}\mathrm{CH}_{4} \text { emissions from rice } \\
\text { field }\end{array}$} & $\mathrm{EFc}$ & $1.30 \times 10-3 \mathrm{tCH} 4$ ha -1 day -1 & [41] \\
\hline & SFw & 0.52 & [41] \\
\hline & SFP & 0.68 & [41] \\
\hline & SFm & 1 & [41] \\
\hline
\end{tabular}

\subsection{Decoupling Index}

In this article, the decoupling index $(D I)$ is used to indicate the degree of decoupling of GHG emissions from crop production, following Equation (9):

$$
\mathrm{DI}=\% \Delta \mathrm{CF} / \% \Delta \mathrm{Y}=\left(\mathrm{CF}_{\mathrm{j}} / \mathrm{CF}_{\mathrm{j}-1}-1\right) /\left(\mathrm{Y}_{\mathrm{j}} / \mathrm{Y}_{\mathrm{j}-1}-1\right),
$$

where $\% \triangle C F$ is the percentage change in GHG emissions from crop production, and $C F_{j}$ and $C F_{j-1}$ denote GHG emissions in a target year $j$ and the base year $j-1 ; \% \Delta Y$ is the percentage change in crop yield, and $Y_{j}$ and $Y_{j-1}$ denote the crop yield in a target year $j$ and the base year $j-1$, respectively. Six decoupling index values are shown in Table 2.

Table 2. Degrees of decoupling GHG emissions from crop production.

\begin{tabular}{ll}
\hline Decoupling Degree & Relationship between GHG Emissions and Crop Production \\
\hline Strong decoupling & $\Delta \mathrm{Y}>0, \Delta \mathrm{CF} \leq 0, \mathrm{DI} \leq 0$ \\
Weak decoupling & $\Delta \mathrm{Y}>0, \Delta \mathrm{CF}>0,0<\mathrm{DI}<1$ \\
Recessive decoupling & $\Delta \mathrm{Y}<0, \Delta \mathrm{CF}<0, \mathrm{DI} \geq 1$ \\
Expansive coupling & $\Delta \mathrm{Y}>0, \Delta \mathrm{CF}>0, \mathrm{DI} \geq 1$ \\
Weak coupling & $\Delta \mathrm{Y}<0, \Delta \mathrm{CF}<0,0<\mathrm{DI}<1$ \\
Strong coupling & $\Delta \mathrm{Y}<0, \Delta \mathrm{CF} \geq 0, \mathrm{DI} \leq 0$ \\
\hline
\end{tabular}

\subsection{Study Area and Data Sources}

The HLRA is located in northeast China and includes nine branches with an area of $57,600 \mathrm{~km}^{2}$ (Figure 2). There are four main grain crops in the study area: rice, maize, soybeans, and wheat. Rice and maize are main crops generally grown in the humid eastern branches, whereas soybeans and wheat are the main crops grown in the semi-humid western branches. These four crops accounted for $97 \%$ of the total output in 2015. The comprehensive utilization rate of agricultural mechanization is over $94 \%$, and these commodity grains achieve $91 \%$ of their annual crop yield in the HLRA, which has improved national food security. 


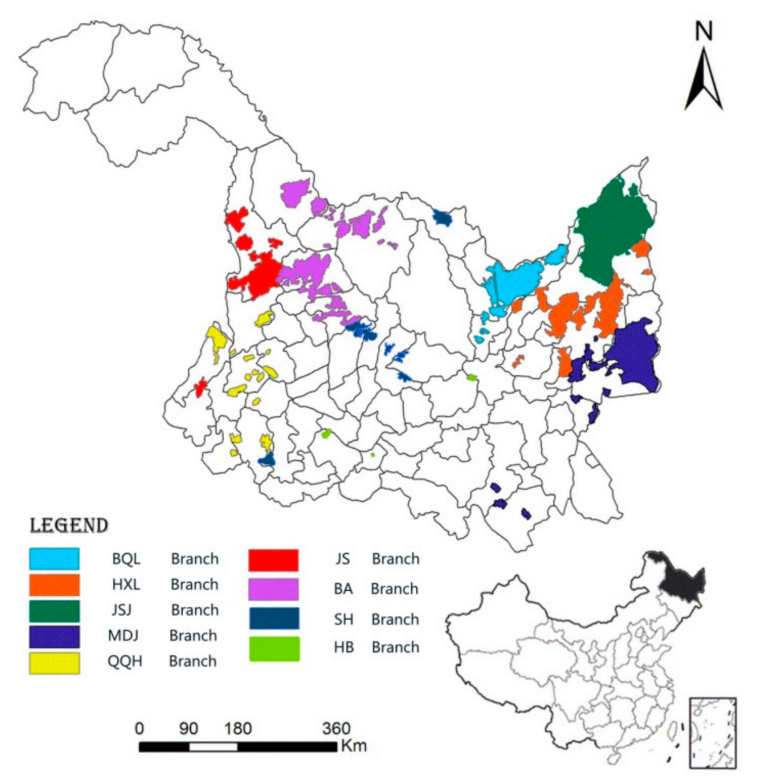

Figure 2. Location of the study area.

Data for quantifying GHG emissions from agricultural inputs or sources were collected from the National Cost-Benefit Survey for Agricultural Products (2001-2015). Crop yield and planting area data were collected from the Statistical Yearbook of the Heilongjiang Land Reclamation Area (2002-2016), and data for quantifying $\mathrm{CH}_{4}$ emissions from the rice paddy, including the rice cultivation and growing periods, were obtained from field research and existing literature [26,30,39-41].

\section{Results and Analysis}

\subsection{Relationship between Crop Yield and Carbon Footprint}

The changes in the crop yields and the CFs of four crops in the HLRA (2001-2015) are shown in Figure 3; the correlation coefficient, R, between crop yield and the CF was 0.994 at a significance level of 0.01 . Using crop yield as the independent variable, $x$, and the $C F$ as the dependent variable, $y$, the best-fit linear equation relating these two variables was $y=0.2227 x+72.383$. The $R^{2}$ and adjusted $R^{2}$ values of this equation were 0.988 and 0.987 , respectively, which indicated a close relationship between GHG emissions and crop production in the HLRA.

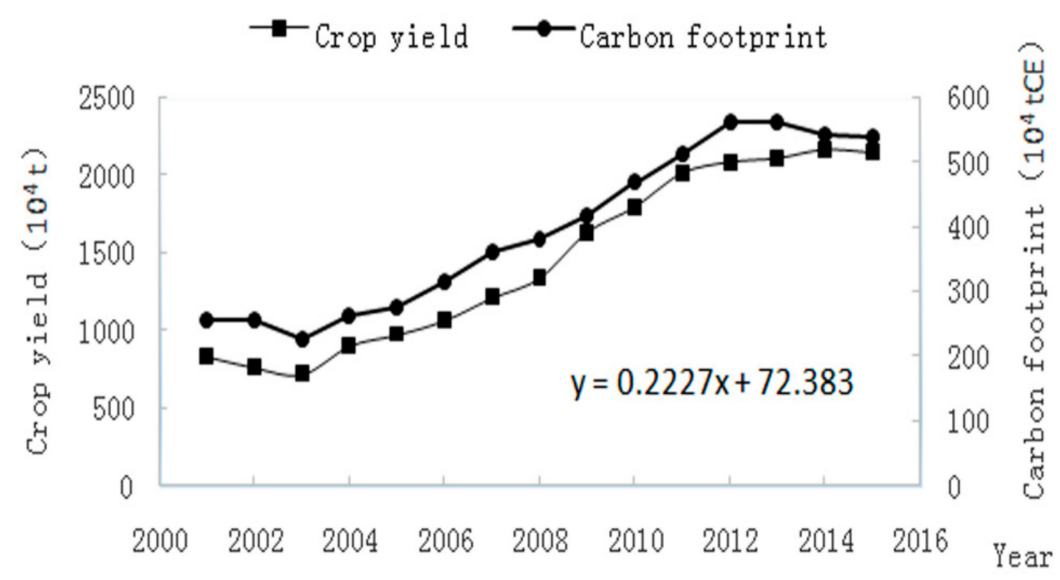

Figure 3. Relationship between carbon footprint and crop yield in the HLRA (2001-2015). 


\subsection{Decoupling GHG Emissions from Crop Production}

According to Table 2, the results of decoupling GHG emissions from crop production during 2001-2015 in the HLRA are shown in Table 3, and the results based on the average value in the period 2001-2015 are shown in Table 4.

Table 3. Decoupling GHG emissions from crop production in the HLRA.

\begin{tabular}{ccccccc}
\hline Year & $\begin{array}{c}\text { Crop Yield } \\
\left(\mathbf{1 0}^{\mathbf{4}} \mathbf{t}\right)\end{array}$ & $\begin{array}{c}\text { Growth Rate of } \\
\text { Crop Yield (\%) }\end{array}$ & CF (104 $\mathbf{t C E})$ & $\begin{array}{c}\text { Growth Rate of } \\
\text { CF (\%) }\end{array}$ & DI & Decoupling Degree \\
\hline 2001 & 832.17 & - & 255.72 & - & - & \\
2002 & 761.31 & -8.52 & 254.98 & -0.29 & 0.03 & Weak coupling \\
2003 & 717.41 & -5.77 & 226.22 & -11.28 & 1.95 & Recessive decoupling \\
2004 & 901.22 & 25.62 & 262.11 & 15.87 & 0.62 & Weak decoupling \\
2005 & 973.10 & 7.98 & 275.83 & 5.23 & 0.66 & Weak decoupling \\
2006 & 1065.11 & 9.46 & 316.12 & 14.61 & 1.54 & Expansive coupling \\
2007 & 1210.07 & 13.61 & 360.04 & 13.89 & 1.02 & Expansive coupling \\
2008 & 1337.51 & 10.53 & 381.27 & 5.9 & 0.56 & Weak decoupling \\
2009 & 1631.90 & 22.01 & 415.27 & 8.92 & 0.41 & Weak decoupling \\
2010 & 1794.78 & 9.98 & 467.96 & 12.69 & 1.27 & Expansive coupling \\
2011 & 2014.16 & 12.22 & 512.72 & 9.56 & 0.78 & Weak decoupling \\
2012 & 2085.14 & 3.52 & 560.7 & 9.36 & 2.66 & Expansive coupling \\
2013 & 2109.67 & 1.18 & 559.8 & -0.16 & -0.14 & Strong decoupling \\
2014 & 2165.06 & 2.63 & 542.11 & -3.16 & -1.2 & Strong decoupling \\
2015 & 2146.15 & -0.87 & 537.46 & -0.86 & 0.99 & Weak coupling \\
\hline
\end{tabular}

Table 4. Decoupling GHG emissions from crop production in the HLRA (average of the years 2001-2015).

\begin{tabular}{ccccccc}
\hline Branch & $\begin{array}{c}\text { Crop Yield } \\
\left(\mathbf{1 0}^{\mathbf{4}} \mathbf{t}\right)\end{array}$ & $\begin{array}{c}\text { Growth Rate of } \\
\text { Crop Yield (\%) }\end{array}$ & CF (104) $\mathbf{t C E )}$ & $\begin{array}{c}\text { Growth Rate of } \\
\text { CF (\%) }\end{array}$ & DI & Decoupling Degree \\
\hline BQL & 220.33 & 6.56 & 57.72 & 5.24 & 0.8 & Weak decoupling \\
HXL & 283.32 & 7.13 & 70.3 & 3.67 & 0.51 & Weak decoupling \\
JSJ & 438.37 & 9.58 & 125.94 & 8.72 & 0.91 & Weak decoupling \\
MDJ & 277.5 & 5.33 & 73.87 & 3.71 & 0.7 & Weak decoupling \\
BA & 122.37 & 11.79 & 21.5 & 3.91 & 0.33 & Weak decoupling \\
JS & 93.06 & 11.15 & 12.81 & 1.39 & 0.12 & Weak decoupling \\
QQH & 67.357 & 9.82 & 15.56 & 6.21 & 0.63 & Weak decoupling \\
SH & 41.46 & 6.72 & 11.98 & 3.84 & 0.57 & Weak decoupling \\
HB & 12.68 & 11.93 & 4.84 & 8.37 & 0.7 & Weak decoupling \\
\hline
\end{tabular}

According to Table 3, during 2001-2015, strong decoupling occurred for two years, weak decoupling occurred for five years, and recessive decoupling occurred for one year, which indicated that changes in carbon intensity were variable during this period and largely composed of weak decoupling. GHG emissions of crop production did not increase in proportion with crop yield in the HLRA for 2013 and 2014. Expansive coupling occurred for four years, and weak coupling occurred for two years. One of these weakly increasing years, 2015, followed two years of strong decoupling, which suggests that HLRA continues to face both challenges and opportunities as low-carbon agriculture continues to develop.

According to Table 4, from the perspective of the branch scale, all branches experienced weak decoupling between crop production and GHG emissions when considering the mean change from 2001-2015. This analysis revealed the potential for the HLRA to experience strong decoupling with continued progress.

\subsection{Example: Decoupling GHG Emissions from Rice Production}

Rice in the HLRA is economically and environmentally important to China, both as the largest green food base and because of its high-quality rice varieties. On average, rice acreage was $48 \%$ of the total grain-planting area, and rice accounted for $62 \%$ of the total grain yield in the HLRA during 
2001-2015. During these years, GHG emissions from rice production accounted for $80 \%$ of the total HLRA CF, with maize, soybeans, and wheat contributing $11 \%, 7 \%$, and $2 \%$ to the total $C F$, respectively. Further results of decoupling GHG emissions from rice production with regard to the whole HLRA and the branch scale over 2001-2015 are shown in Tables 5 and 6.

Table 5. Decoupling GHG emissions from rice production in the HLRA.

\begin{tabular}{ccccccc}
\hline Year & $\begin{array}{c}\text { Rice Yield } \\
(\mathbf{1 0 4} \mathbf{t})\end{array}$ & $\begin{array}{c}\text { Growth Rate of } \\
\text { Rice Yield (\%) }\end{array}$ & $\begin{array}{c}\text { CF of Rice } \\
\left.\mathbf{( 1 0}^{\mathbf{4}} \mathbf{t C E}\right)\end{array}$ & $\begin{array}{c}\text { Growth Rate of } \\
\text { CF of Rice (\%) }\end{array}$ & DI & Decoupling Degree \\
\hline 2001 & 527.42 & - & 194.14 & - & - & \\
2002 & 452.77 & -14.15 & 197.92 & 1.94 & -0.14 & Strong coupling \\
2003 & 424.16 & -6.32 & 165.73 & -16.26 & 2.57 & Recessive decoupling \\
2004 & 528.62 & 24.63 & 195.99 & 18.26 & 0.74 & Weak decoupling \\
2005 & 573.43 & 8.48 & 209.58 & 6.93 & 0.82 & Weak decoupling \\
2006 & 682.5 & 19.02 & 250.45 & 19.5 & 1.03 & Expansive coupling \\
2007 & 798.07 & 16.93 & 288.25 & 15.09 & 0.89 & Weak decoupling \\
2008 & 842.18 & 5.53 & 307.51 & 6.68 & 1.21 & Expansive coupling \\
2009 & 927.32 & 10.11 & 322.21 & 4.78 & 0.47 & Weak decoupling \\
2010 & 1094.39 & 18.02 & 373.24 & 15.84 & 0.88 & Weak decoupling \\
2011 & 1278.91 & 16.86 & 422.52 & 13.2 & 0.78 & Weak decoupling \\
2012 & 1370.42 & 7.16 & 464.38 & 9.91 & 1.38 & Expansive coupling \\
2013 & 1385.67 & 1.11 & 464.6 & 0.05 & 0.05 & Weak decoupling \\
2014 & 1329.35 & -4.06 & 443.6 & -4.52 & 1.11 & Recessive decoupling \\
2015 & 1291.51 & -2.85 & 435.93 & -1.73 & 0.61 & Weak coupling \\
\hline
\end{tabular}

Table 6. Decoupling GHG emissions from rice production at the branch scale of the HLRA (average of the years 2001-2015).

\begin{tabular}{ccccccc}
\hline Branch & $\begin{array}{c}\text { Rice Yield } \\
\left(\mathbf{1 0}^{\mathbf{4}} \mathbf{t}\right)\end{array}$ & $\begin{array}{c}\text { Growth Rate of } \\
\text { Rice Yield (\%) }\end{array}$ & $\begin{array}{c}\text { CF of Rice } \\
\left.\mathbf{( 1 0}^{\mathbf{4}} \mathbf{t C E}\right)\end{array}$ & $\begin{array}{c}\text { Growth Rate of } \\
\text { CF of Rice (\%) }\end{array}$ & DI & Decoupling Degree \\
\hline BQL & 127.57 & 7.68 & 45.46 & 6.79 & 0.88 & Weak decoupling \\
HXL & 151.36 & 4.45 & 54 & 3.24 & 0.73 & Weak decoupling \\
JSJ & 384.88 & 11.03 & 117.57 & 9.95 & 0.9 & Weak decoupling \\
MDJ & 205.39 & 3.91 & 64.17 & 3.39 & 0.87 & Weak decoupling \\
BA & 3.7 & 57.74 & 4.62 & 5.38 & 0.09 & Weak decoupling \\
JS & 3.54 & 41.43 & 4.26 & 10.15 & 0.24 & Weak decoupling \\
QQH & 40.09 & 10.23 & 13.01 & 6.74 & 0.66 & Weak decoupling \\
SH & 16.18 & 1.3 & 7.17 & 2.36 & 1.82 & Expansive coupling \\
HB & 6.44 & 8.35 & 3.50 & 7.85 & 0.94 & Weak decoupling \\
\hline
\end{tabular}

According to Table 5, weak decoupling was the most common outcome, observed for seven years of the study period, whereas recessive decoupling was observed for two years. No strong decoupling was observed, but expansive coupling was observed for three years, and both strong coupling and weak coupling were observed for one year each. In 2003 and 2014, when the growth rate of CF of rice production decreased by $-16.26 \%$ and $-4.52 \%$, respectively, rice yield decreased accordingly by $-6.32 \%$ and $-4.06 \%$ compared with the previous year, respectively. The desired decoupling between GHG emissions and rice production was therefore not observed during these years. Worse than that, strong coupling was observed in 2002, when the CF of rice production increased by $1.94 \%$, despite a decrease in rice yield of $14.15 \%$. Both increases and decreases in carbon intensity in rice production were observed; even weak coupling occurred, most recently in 2015, and there was no clear trend across the time series.

Seen from the branch scale over 2001-2015 (Table 6), on average, each branch except the SH branch achieved a weak decoupling of GHG emissions from rice production. However, the rate of rice yield growth (1.3\%) failed to exceed that of the rice CF growth rate $(2.36 \%)$ in the $\mathrm{SH}$ branch, which led to the degree of expansive coupling. 


\section{Discussion}

Generally, we can evaluate GHG emissions based on the reduction in the carbon footprint; however, some indeterminacy remains when diagnosing the effective quantity of emissions reduction, and we thus need to link it with the economic development process. As a supplementary method, the frame of decoupling focuses on the relationship between economic growth and environmental pressure, which helps to create a better understanding of the nature of green growth, further remove barriers to decoupling, and encourage policies towards decoupling [5]. Recently, many studies have used a panel VAR approach or a log mean division index (LMDI) decomposition method to analyze the factors that affect GHG emissions in the manufacturing or transport sector [12,42-45]; however, these methods are addressed less in the decoupling of GHG emissions from the agricultural sector. In this discussion section, we compare the carbon footprint of crop production in the HLRA within different countries, analyze the composition of carbon footprint, and further focus on rice production.

\subsection{Comparative Analysis of Carbon Footprint}

According to Equation (7) for carbon intensity in crop yield, the $\mathrm{CF}_{Y}$ in the HLRA varied by crop. On average, rice production possessed the highest $\mathrm{CF}_{Y}\left(0.36 \mathrm{tCEt}^{-1}\right)$, maize production possessed the lowest $\mathrm{CF}_{\mathrm{Y}}\left(0.12 \mathrm{tCEt}^{-1}\right)$, and the $\mathrm{CF}_{\mathrm{Y}}$ for soybean and wheat production showed intermediate values of $0.19 \mathrm{tCEt}^{-1}$ and $0.21 \mathrm{tCEt}^{-1}$, respectively. Compared with existing research results (Table 7), most $\mathrm{CF}_{Y}$ values of crop production in the HLRA were lower than the average value in China, except for soybeans $\left(0.10 \mathrm{tCEt}^{-1}\right)$, and the $\mathrm{CF}_{Y}$ of soybean and wheat production in the HLRA was close to that of the USA.

Table 7. Comparison of international carbon intensity in crop yield.

\begin{tabular}{cccc}
\hline Country/Region & Crop & $\mathbf{C F}_{\mathbf{Y}}\left(\mathbf{t C E t} \mathbf{- 1}^{\mathbf{1}}\right)$ & Reference \\
\hline HLRA & Rice & 0.36 & \\
& Maize & 0.12 & \\
& Soybeans & 0.19 & \\
& Wheat & 0.21 & \\
\hline China & Rice & 0.80 & {$[25]$} \\
& Maize & 0.33 & {$[25]$} \\
& Soybeans & 0.10 & {$[46]$} \\
& Wheat & 0.65 & {$[25]$} \\
\hline USA & Maize & $0.12-0.25$ & {$[47]$} \\
& Wheat & $0.25-0.35$ & {$[47]$} \\
\hline Canada & Wheat & $0.27-0.50$ & {$[48]$} \\
\hline India & Rice & $1.2-1.5$ & {$[49]$} \\
& Wheat & 0.12 & {$[49]$} \\
\hline
\end{tabular}

We observe a better relationship between crop production and GHG emissions in the HLRA than in other regions of the world. However, as various values of the decoupling index were observed, it did not appear that the carbon intensity of agriculture in the HLRA steadily decreased.

\subsection{Composition Analysis of Carbon Footprint}

The compositions of the CFs for the four major crops in the HLRA during the period 2001-2015 are shown in Figure 4. On average, $\mathrm{CH}_{4}$ was the biggest contributor $(41 \%)$ to the total $\mathrm{CF}$, which indicated that rice production was the main source of GHG emissions in the HLRA. Direct $\mathrm{N}_{2} \mathrm{O}$ emissions and indirect emissions from $\mathrm{N}$ fertilizer input together represented the second-biggest contributor $(25 \%)$, with electricity for irrigation (11\%) representing the third-largest contributor to the CF. All other sources, including P fertilizer (4\%), seed (4\%), plastic films (6\%), diesel $(7 \%)$, and $\mathrm{K}$ fertilizer and pesticides $(1 \%)$, were minor contributors to the HLRA CF. 


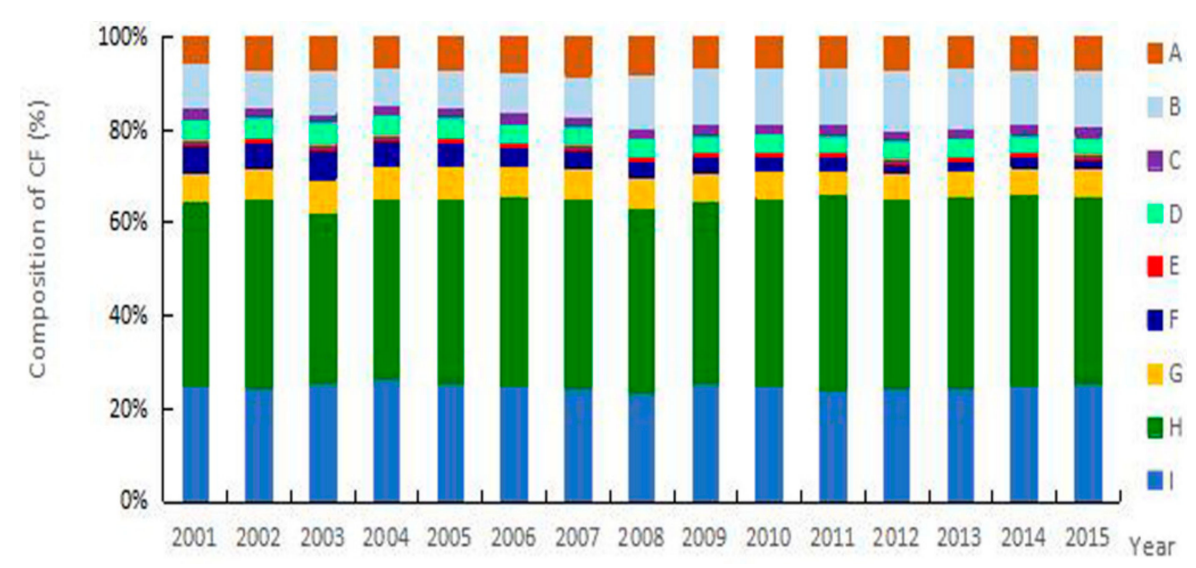

Figure 4. Composition of CFs for crop production in the HLRA (2001-2015). A: Plastic film; B: Electricity; C: Pesticide; D: P fertilizer; E: K fertilizer; F: Seed; G: Diesel; $\mathrm{H}_{2} \mathrm{CH}_{4}$; I: N fertilizer $+\mathrm{N}_{2} \mathrm{O}$.

Agricultural material inputs or sources to the HLRA CF are shown in Figure 5. For rice production, $51 \%$ of the $\mathrm{CF}$ was derived from $\mathrm{CH}_{4}$ emissions, followed by the sum of direct $\mathrm{N}_{2} \mathrm{O}$ emissions and indirect emissions from $\mathrm{N}$ fertilizer use $(16.06 \%)$, electricity for irrigation $(13.98 \%)$ and plastic film $(8.89 \%)$. The remaining five inputs and farming operations amounted to $10.07 \%$ of the total CF.

In contrast, the sum of direct $\mathrm{N}_{2} \mathrm{O}$ emissions and indirect emissions from $\mathrm{N}$ fertilizer use was the largest contributor to the CFs of dry crops (maize, soybeans, and wheat), accounting for $72.9 \%$, $44 \%$, and $49.5 \%$ of the CF for maize, soybean, and wheat production, respectively. The second largest contributor to the total CFs for both maize and soybean production was diesel $(12.28 \%$ and $22 \%$, respectively), and seed was the second largest contributor for wheat production (23.3\%), followed by diesel (12.05\%). Overall, $\mathrm{N}$ fertilizer input and $\mathrm{N}_{2} \mathrm{O}$ from $\mathrm{N}$ fertilizer use were the dominant sources of GHG emissions in dry crop production, although $\mathrm{CH}_{4}$ was the dominant source of GHG emissions in rice production. In contrast, pesticides contributed a small amount to each crop's $\mathrm{CF}$, especially for rice production $(0.4 \%)$.

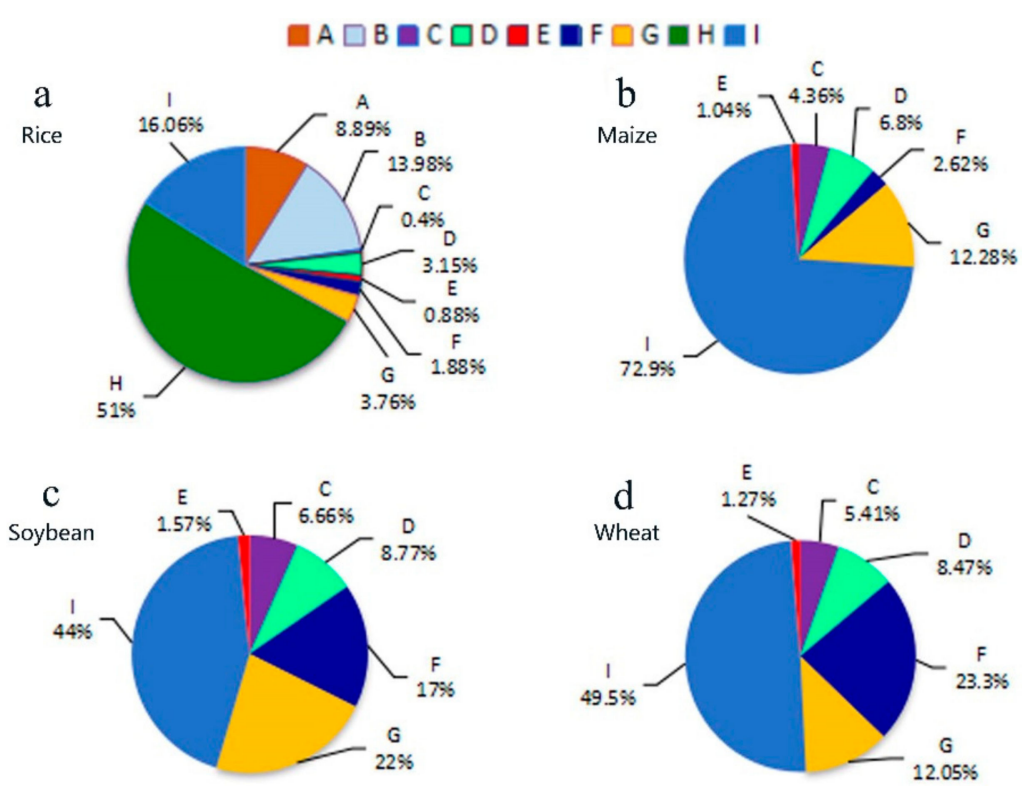

Figure 5. Composition of CFs based on crop structure in the HLRA. (Average of the years 2001-2015). A: Plastic film; B: Electricity; C: Pesticide; D: P fertilizer; E: K fertilizer; F: Seed; G: Diesel; $\mathrm{H}: \mathrm{CH}_{4}$; I: $\mathrm{N}$ fertilizer $+\mathrm{N}_{2} \mathrm{O}$. 


\subsection{Analysis of the CF of Rice Production}

As reported above, rice production played an important role in the HLRA and constituted the vast majority of the $\mathrm{CF}$ in this region $(80 \%)$. In recent decades, eight branches (except the $\mathrm{SH}$ branch) experienced a weak decoupling between crop production and GHG emissions (Table 6). Here, we take the JSJ branch and the SH branch of the HLRA for comparative analysis (Figures 6 and 7).

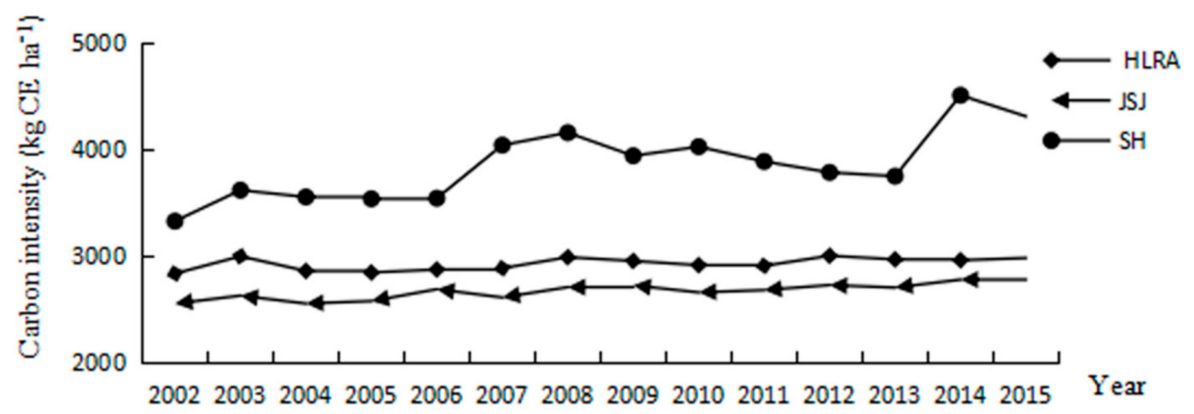

Figure 6. Carbon intensity in area for rice production in the JSJ branch and the SH branch (2001-2015).

The JSJ branch is the largest branch in the HLRA, and its rice planting area and rice yield occupied $41 \%$ and $43 \%$ of the HLRA total. In contrast, the rice planting area and rice yield in the SH branch each occupied $2 \%$ of the HLRA total. There was a distinct difference in trends between CF and rice yield between these two branches (Figure 6). According to Equation (8) for carbon intensity per area, the $\mathrm{CF}_{\mathrm{A}}$ of rice production in the JSJ branch fluctuated from $2539 \mathrm{kgCEha}^{-1}$ to $2775 \mathrm{kgCEha}^{-1}$, which was below the average $\mathrm{CF}_{\mathrm{A}}$ in the HLRA $\left(2919 \mathrm{kgCEha}^{-1}\right)$, whereas the $\mathrm{CF}_{\mathrm{A}}$ of rice production in the $\mathrm{SH}$ branch fluctuated from $3323 \mathrm{kgCEha}^{-1}$ to $4503 \mathrm{kgCEha}^{-1}$.
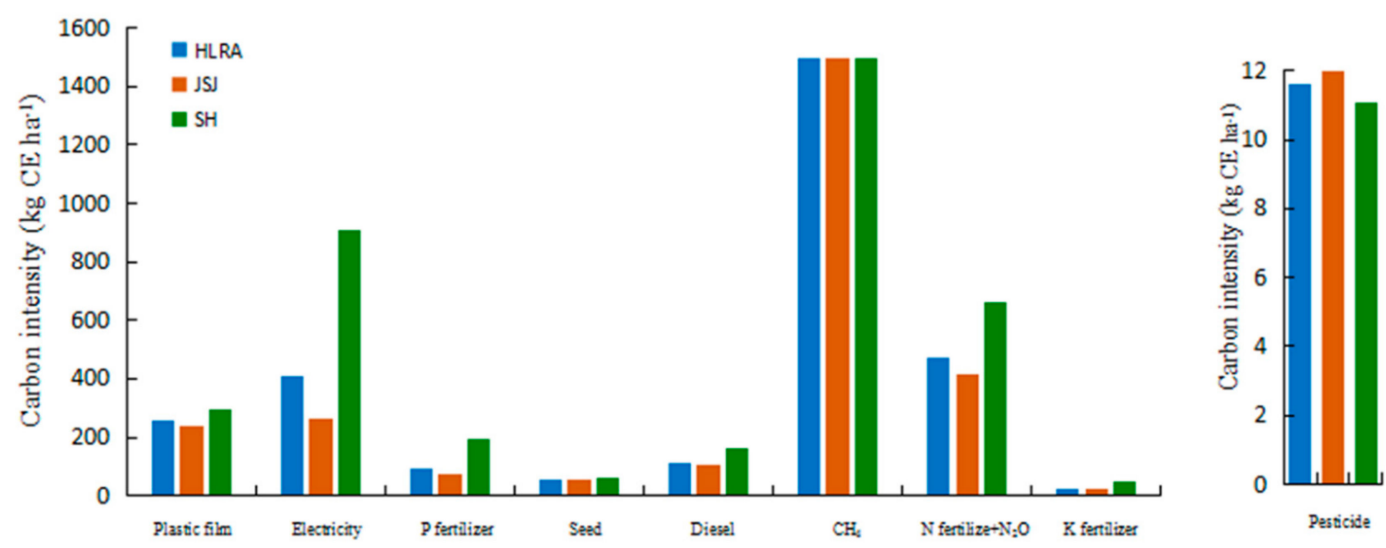

Figure 7. Carbon intensity per area for rice production in the JSJ branch and the SH branch (average of the years 2001-2015).

The $\mathrm{SH}$ branch required more electricity for irrigation, more fertilizer input (especially more $\mathrm{N}$ fertilizer), and more diesel input per unit area, all of which contributed to a higher $\mathrm{CF}_{\mathrm{A}}$ for rice production (Figure 7). It is clear that high material inputs with low utilization efficiency contributed to its degree of expansive coupling. Based on this result, we suggest targeted measures for the SH branch to mitigate GHG emissions from rice production, such as decreasing agricultural material inputs (including fertilizers, electricity for irrigation, diesel, and plastic films), improving the utilization efficiency of agricultural material inputs and increasing agricultural productivity. 


\section{Conclusions}

In this paper, a decoupling index based on carbon footprint and crop yield was used to examine the relationship between crop production and GHG emissions in the HLRA during the years 2001-2015. The results indicated that various decoupling degrees (including strong decoupling, weak decoupling, and recessive decoupling) occurred during more than half of the study phase across the entire HLRA, although each branch showed weak decoupling based on the average value from 2001 to 2015 . In addition, rice production constituted $80 \%$ of the total CF in the HLRA, and weak decoupling occurred more frequently at the scale of the entire study area and at the branch scale (except for the $\mathrm{SH}$ branch, which showed expansive coupling).

Seen from the results of the decoupling analysis, although a high appearance frequency of weak decoupling occurred during 2001-2015 in the HLRA, the status of weak decoupling was not steady, which highlights both pressures and challenges for the HLRA as it develops towards green growth. We also found that high material inputs with low utilization efficiency contributed to a poor relationship between crop production and GHG emissions and that fertilizer was an important contributor to the total CF of crop production. Since it is the major source of GHG emissions from agriculture in the HLRA, we should pay more attention to rice production, in particular for the SH branch.

The current work of decoupling analysis aims to examine the relationship between GHG emissions and crop production, using HLRA as an example. In fact, there is a limitation to the decoupling concept, which lacks a direct contact with the environmental process. Based on the results of decoupling analysis, next we will borrow from the experience of others and use the LMDI decomposition methodology to analyze factors that affect GHG emissions in crop production processes, in view of the activity effect, the structure effect, and the intensity effect. Further integrating more detailed information about GHG emissions from crop production processes could contribute to more targeted suggestions for low-carbon agriculture.

Author Contributions: Q.Y. designed the research. C.X. collected the data and X.Z. analyzed the data. Y.Z. wrote the manuscript. All authors read, revised, and approved the final manuscript.

Funding: The work in this paper was supported by the National Natural Science Funds of China (Grant No. 41571115, 41271555, 41630749, and 41571405) and the Fundamental Research Funds for the Central Universities (2412018ZD012).

Conflicts of Interest: The authors declare no conflict of interest.

\section{References}

1. Arrow, K.; Bolin, B.; Costanza, R.; Dasgupta, P.; Folke, C.; Holling, C.S.; Jansson, B.O.; Levin, S.; Maler, K.G.; Perrings, C.; et al. Economic Growth, Carrying Capacity and the Environment. Science 1995, 268, 520-521. [CrossRef] [PubMed]

2. Holdren, J.P. Science and Technology for Sustainable Well-being. Science 2008, 319, 424-434. [CrossRef]

3. Magazzino, C. The Relationship among Economic Growth, $\mathrm{CO}_{2}$ Emissions and Energy Use in the APEC Countries: A Panel VAR Approach. Environ. Syst. Decis. 2017, 37, 353-366. [CrossRef]

4. United Nations Environment Programme. Options for Decoupling Economic Growth from Water Use and Water Pollution; Report of the International Resource Panel Working Group on Sustainable Water Management; UNEP: Nairobi, Kenya, 2015; pp. 1-73.

5. United Nations Environment Programme. Decoupling 2: Technologies, Opportunities and Policy Options; A Report of the Working Group on Decoupling to the International Resource Panel; UNEP: Nairobi, Kenya, 2014; pp. 1-158.

6. Grossman, G.M.; Krueger, A.B. Economic Growth and the Environment. Q. J. Econ. 1995, 110, $353-377$. [CrossRef]

7. Organisation for Economic Co-operation and Development. Indicators to Measure Decoupling of Environmental Pressure from Economic Growth; OECD: Paris, France, 2002; pp. 1-3.

8. Tapio, P. Towards a Theory of Decoupling: Degrees of Decoupling in the EU and the Case of Road Traffic in Finland between 1970 and 2001. J. Transp. Policy 2005, 12, 137-151. [CrossRef] 
9. Diakoulaki, D.; Mandaraka, M. Decomposition Analysis for Assessing the Progress in Decoupling Industrial Growth from $\mathrm{CO}_{2}$ Emissions in the EU Manufacturing Sector. Energy Econ. 2007, 29, 636-664. [CrossRef]

10. Roman, R.; Cansino, J.M.; Botia, C. How far is Colombia from Decoupling? Two-level decomposition analysis of energy consumption changes. Energy 2018, 148, 687-700. [CrossRef]

11. Schandl, H.; Hatfield-Dodds, S.; Wiedmann, T.; Geschke, A.; Cai, Y.; West, J.; Newth, D.; Baynes, T.; Lenzen, M.; Owen, A. Decoupling Global Environmental Pressure and Economic Growth: Scenarios for Energy Use, Materials Use and Carbon Emissions. J. Clean. Prod. 2016, 132, 45-56. [CrossRef]

12. Roman, R.; Cansino, J.M.; Rodas, J.A. Analysis of the Main Drivers of $\mathrm{CO}_{2}$ Emissions Changes in Colombia (1990-2012) and its Political Implications. Renew. Energy 2018, 116, 402-411. [CrossRef]

13. United Nations Environment Programme. Decoupling Natural Resource Use and Environmental Impacts from Economic Growth; A Report of the Working Group on Decoupling to the International Resource Panel; UNEP: Nairobi, Kenya, 2011; pp. 1-174.

14. Intergovernmental Panel on Climate Change. Climate change 2007: The Physical Science Basis. In Contribution of the Working Group I to the Fourth Assessment Report of the Intergovernmental Panel on Climate Change; Cambridge University Press: Cambridge, UK; New York, NY, USA, 2007; Available online: http:/ / www.ipcc.ch/pdf/assessment-report/ar4/syr/ar4_syr.pdf (accessed on 6 June 2018).

15. Intergovernmental Panel on Climate Change. Climate Change 2013: The Physical Science Basis. In Contribution of Working Group I to the Fifth Assessment Report of the Intergovernmental Panel on Climate Change; Cambridge University Press: Cambridge, UK; New York, NY, USA, 2013; pp. 1-1535.

16. Perry, S.; Klemes, J.; Bulatov, I. Integrating Waste and Renewable Energy to Reduce the Carbon Footprint of Locally Integrated Energy Sectors. Energy 2008, 33, 1489-1497. [CrossRef]

17. Hillier, J.; Hawes, C.; Squire, G.; Hilton, A.; Wale, S.; Smith, P. The Carbon Footprints of Food Crop Production. Int. J. Agric. Sustain. 2009, 7, 107-118. [CrossRef]

18. Liu, Y.; Xiao, H.W.; Zikhali, P.; Lv, Y.K. Carbon Emissions in China: A Spatial Econometric Analysis at the Regional Level. Sustainability 2014, 6, 6005-6023. [CrossRef]

19. Smith, P.; Martino, D.; Cai, Z.C.; Gwary, D.; Janzen, H.; Kumar, P.; McCarl, B.; Ogle, S.; O’Mara, F.; Rice, C.; et al. Greenhouse Gas Mitigation in Agriculture. Philos. Trans. Biol. Sci. 2008, 363, 789-813. [CrossRef] [PubMed]

20. McDougall, F.; White, P.; Franke, M.; Hindle, P. Integrated Solid Waste Management: A Life Cycle Inventory; Blackwell Science: London, UK, 2001.

21. Lal, R. Carbon Emission from Farm Operations. Environ. Int. 2004, 30, 981-990. [CrossRef] [PubMed]

22. Ponsioen, T.C.; Blonk, T.J. Calculating Land Use Change in Carbon Footprints of Agricultural Products as an Impact of Current Land Use. J. Clean. Prod. 2012, 28, 120-126. [CrossRef]

23. Clair, S.S.; Hiller, J.; Smith, P. Estimating the pre-harvest greenhouse gas costs of energy crop production. Biomass Bioenergy 2008, 32, 442-452. [CrossRef]

24. Knudsen, M.T.; Meyer-Aurich, A.; Olesen, J.E.; Chirinda, N.; Hermansen, J.E. Carbon footprints of crops from organic and conventional arable crop rotations-Using a life cycle assessment approach. J. Clean. Prod. 2014, 64, 609-618. [CrossRef]

25. Yan, M.; Cheng, K.; Luo, T.; Yan, Y.; Pan, G.; Robert, M.R. Carbon footprint of grain crop production in china-based on farm survey data. J. Clean. Prod. 2015, 104, 130-138. [CrossRef]

26. Huang, X.; Chen, C.; Chen, M.; Song, Z.; Deng, A.; Zhang, J.; Zheng, C.; Zhang, W. Carbon Footprints of Major Staple Grain Crops Production in Three Provinces of Northeast China during 2004-2013. Chin. J. Appl. Ecol. 2016, 27, 3307-3315.

27. Dubey, A.; Lal, R. Carbon Footprint and Sustainability of Agricultural Production Systems in Punjab, India, and Ohio, USA. J. Crop Improv. 2009, 23, 332-350. [CrossRef]

28. Cheng, K.; Yan, M.; Nayak, D.; Smith, P.; Pan, G.; Zheng, J. Carbon Footprint of Crop Production in China: An Analysis of National Statistics Data. Sci. Agric. Sin. 2015, 153, 422-431. [CrossRef]

29. Xue, J.; Pu, C.; Liu, S.; Zhao, X.; Zhang, R.; Chen, F.; Xiao, X.; Zhang, H. Carbon and Nitrogen Footprint of Double Rice Production in Southern China. Ecol. Indic. 2016, 64, 249-257. [CrossRef]

30. Wang, X.; Zhao, X.; Wang, Y.; Xue, J.; Zhang, H. Assessment of the Carbon Footprint of Rice Production in China. Resour. Sci. 2017, 39, 713-722.

31. Huang, Y.; Zhang, W.; Zheng, X.; Han, S.; Yu, Y. Estimates of Methane Emission from Chinese Paddy Fields by Linking A Model to GIS Database. Acta Ecol. Sin. 2006, 6, 980-988. [CrossRef] 
32. Gan, Y.; Liang, B.; May, W.; Malhi, S.S.; Niu, J.; Wang, X. Carbon Footprint of Spring Barley in Relation to Preceding Oilseeds and N Fertilization. Int. J. Life Cycle Assess. 2012, 17, 635-645. [CrossRef]

33. Wang, Y.; Zhao, X.; Li, K.; Wang, X.; Xue, J.; Zhang, H. Dynamics of Carbon Footprint for Wheat Production in the North China Plain. China Popul. Resour. Environ. 2015, S2, 258-261.

34. Dyer, J.A.; Kulshreshtha, S.N.; McConkey, B.G.; Desjardins, R.L. An assessment of fossil fuel energy use and $\mathrm{CO}_{2}$ emissions from farm field operations using a regional level crop and land use database for Canada. Energy 2010, 35, 2261-2269. [CrossRef]

35. Koga, N.; Tsuruta, H.; Tsuji, H.; Nakano, H. Fuel Consumption-derived $\mathrm{CO}_{2}$ Emissions under Conventional and Reduced Tillage Cropping Systems in Northern Japan. Agric. Ecosyst. Environ. 2003, 99, 213-219. [CrossRef]

36. Tian, Y.; Zhang, J.; Li, B. Intensities of Agricultural Carbon Emissions and Their Causes in the Major Grain Producing Areas in China. Prog. Geogr. 2012, 31, 1546-1551.

37. Cheng, K.; Pan, G.; Smith, P.; Luo, T.; Li, L.; Zheng, J.; Zhang, X.; Han, X.; Yan, M. Carbon Footprint of China's Crop Production-An Estimation Using Agro-statistics Data over 1993-2007. Agric. Ecosyst. Environ. 2011, 142, 231-237. [CrossRef]

38. Yang, Q.; Liu, J.; Zhang, Y. Decoupling Agricultural Nonpoint Source Pollution from Crop Production: A Case Study of Heilongjiang Land Reclamation Area, China. Sustainability 2017, 9, 1024. [CrossRef]

39. Zou, J.; Huang, Y.; Zheng, X.; Wang, Y. Quantifying Direct $\mathrm{N}_{2} \mathrm{O}$ Emissions in Paddy Fields during Rice Growing Season in Mainland China: Dependence on Water Regime. Atmos. Environ. 2007, 41, 8030-8042. [CrossRef]

40. Intergovernmental Panel on Climate Change. 2006 IPCC Guidelines for National Greenhouse Gas Inventories; Institute for Global Environmental Strategy: Kanagawa, Japan, 2006.

41. Yan, X.; Yagi, K.; Akiyama, H.; Akimoto, H. Statistical Analysis of the Major Variables Controlling Methane Emission from Rice Fields. Glob. Chang. Biol. 2005, 11, 1131-1141. [CrossRef]

42. Magazzino, C. A Panel VAR Approach of the Relationship among Economic Growth, $\mathrm{CO}_{2}$ Emissions and Energy Use in the ASEAN-6 Countries. Int. J. Energy Econ. Policy 2014, 4, 546-553.

43. Jeong, K.; Kim, S. LMDI Decomposition Analysis of Greenhouse Gas Emissions in the Korean Manufacturing Sector. Energy Policy 2013, 62, 1245-1253. [CrossRef]

44. Ren, S.; Yin, H.; Chen, X. Using LMDI to Analyze the Decoupling of Carbon Dioxide Emissions by China's Manufacturing Industry. Environ. Dev. 2014, 9, 61-75. [CrossRef]

45. Timilsina, G.R.; Shrestha, A. Factors Affecting Transport Sector $\mathrm{CO}_{2}$ Emissions Growth in Latin American and Caribbean Countries: An LMDI Decomposition Analysis. Int. J. Energy Res. 2009, 33, 396-414. [CrossRef]

46. Wang, X. Changes in $\mathrm{CO}_{2}$ Emissions Induced by Agricultural Inputs in China over 1991-2014. Sustainability 2016, 8, 414. [CrossRef]

47. Snyder, C.S.; Bruulsema, T.W.; Jensen, T.L.; Fixen, P.E. Review of Greenhouse Gas Emissions from Crop Production Systems and Fertilizer Management Effects. Agric. Ecosyst. Environ. 2009, 133, 247-266. [CrossRef]

48. Gan, Y.; Liang, C.; Wang, X.; McConkey, B. Lowering Carbon Footprint of Durum Wheat by Diversifying Cropping Systems. Field Crops Res. 2011, 122, 199-206. [CrossRef]

49. Pathak, H.; Jain, N.; Bhatia, A.; Patel, J.; Aggarwal, P.K. Carbon Footprints of Indian Food Items. Agric. Ecosyst. Environ. 2010, 139, 66-73. [CrossRef]

(C) 2018 by the authors. Licensee MDPI, Basel, Switzerland. This article is an open access article distributed under the terms and conditions of the Creative Commons Attribution (CC BY) license (http://creativecommons.org/licenses/by/4.0/). 